\title{
Carbon monoxide: impact on remethylation/transsulfuration metabolism and its pathophysiologic implications
}

\author{
Takako Hishiki • Takehiro Yamamoto • \\ Takayuki Morikawa • Akiko Kubo • \\ Mayumi Kajimura • Makoto Suematsu
}

Received: 30 December 2011 / Revised: 27 January 2012 / Accepted: 31 January 2012 / Published online: 14 February 2012

(C) The Author(s) 2012. This article is published with open access at Springerlink.com

\begin{abstract}
Carbon monoxide (CO) is a gaseous product generated by heme oxygenase (HO), which oxidatively degrades heme. While the stress-inducible HO-1 has well been recognized as an anti-oxidative defense mechanism under stress conditions, recent studies suggest that cancer cells utilize the reaction for their survival. HO-2, the constitutive isozyme, also plays protective roles as a tonic regulator for neurovascular function. Although protective roles of the enzyme reaction and CO have extensively been studied, little information is available on the molecular mechanisms by which the gas exerts its biological actions. Recent studies using metabolomics revealed that $\mathrm{CO}$ inhibits cystathionine $\beta$-synthase (CBS), which generates $\mathrm{H}_{2} \mathrm{~S}$, another gaseous mediator. The CO-dependent CBS inhibition may impact on the remethylation cycle and related metabolic pathways including the methionine salvage pathway and polyamine synthesis. This review focuses on the gas-responsive regulation of metabolic systems, particularly the remethylation and transsulfuration pathways, and their putative implications for cancer and ischemic diseases.
\end{abstract}

Keywords Heme oxygenase $\cdot$ Hydrogen sulfide . Cystathionine $\beta$-synthase - Methylation - Glutathione . Cancer Methionine salvage pathway Epigenetics . Metabolic systems · Gas biology

Heme oxygenase (HO) degrades protoheme-IX by cleaving its $\alpha$-methene bridge into free divalent iron $\left(\mathrm{Fe}^{2+}\right)$,

T. Hishiki · T. Yamamoto · T. Morikawa • A. Kubo •

M. Kajimura $\cdot$ M. Suematsu $(\bowtie)$

Department of Biochemistry, JST, ERATO, Suematsu Gas Biology

Project, School of Medicine, Keio University,

35 Shinanomachi, Shinjuku-ku, Tokyo 160-8582, Japan

e-mail: gasbiology@z6.keio.jp
biliverdin-IX $\alpha$, and carbon monoxide (CO) [1-4]. The reaction uses nicotinamide adenine dinucleotide phosphate (NADPH)-cytochrome P450 reductase as an electron donor system [5, 6] and $\mathrm{O}_{2}$ as the acceptor [7]. In humans, nearly $80 \%$ of the bilirubin in bile derives from hemoglobin heme. Cytochromes P450 constitute another major source of heme that undergoes the HO-dependent degradation. Products of the $\mathrm{HO}$ reaction were regarded as potentially toxic wastes destined only for excretion. However, this changed when evidence emerged for physiologic roles of bilirubin-IX $\alpha$, a potent anti-oxidant generated through biliverdin reductase [8-11].

The HO/CO system serves as a neurovascular regulator, as $\mathrm{CO}$ has a modest ability to activate soluble guanylate cyclase [12], a receptor of NO [13, 14]. However, a variety of biological responses specifically triggered by $\mathrm{CO}$ have attracted attention and led to a series of macromolecular receptors for $\mathrm{CO}$ that do not respond to NO. This article focuses on the interaction between the $\mathrm{HO} / \mathrm{CO}$ system and cystathionine $\beta$-synthase (CBS), which is a rate-limiting enzyme regulating methionine metabolism and transsulfuration pathway that serves as an $\mathrm{H}_{2} \mathrm{~S}$-generating system [15-19].

\section{Identification of cystathionine $\beta$-synthase as a CO-regulated protein by metabolomics}

The transcriptional activator CooA in the photosynthetic bacteria Rhodospirillum rubrum is the first example of a heme protein in which $\mathrm{CO}$ plays a physiological role [20]. Only the CO-bound form of CooA binds to its target DNA and acts as a transcriptional activator [20-22]. In mammals, the heme protein neuronal PAS domain protein 2 (NPAS2) was reported to be a specific CO sensor [23, 24]. NPAS2 
was identified as a member of the basic-helix-loop-helix (bHLH) family of transcription factors expressed in the forebrain. The resonance Raman spectra indicated that $\mathrm{CO}$ coordinated to the heme iron histidine on the proximal side, whereas NO did not bind to the heme group [25]. CO has been proposed to regulate the formation of a complex between NPAS2 and BMAL1, another bHLH transcription factor, that regulates the circadian rhythms [23].

Many heme enzymes including cytochromes P450 were once considered putative $\mathrm{CO}$-sensitive signal transducers [26-28]. However, the ferrous heme of these enzymes has been found to be sensitive to both $\mathrm{CO}$ and $\mathrm{NO}$, ruling them out as CO-specific sensors. On the other hand, CBS, the "pseudo-cytochrome P450", was found to be a strong candidate for a CO-specific sensor. In vitro studies using recombinant CBS reported that $\mathrm{CO}$, but not $\mathrm{NO}$, acted as a competitive inhibitor of CBS $[27,29]$ with the $K_{\mathrm{i}}$ value of several micromolar, much smaller than that for NO $(200 \mu \mathrm{M})$. CO inhibits recombinant rat CBS by stabilizing the 6-coordinated structure of the heme. By comparison, NO binds to heme, but stabilizes the 5-coordinated structure. CBS was first identified as $\mathrm{H} 450$ where the addition of $\mathrm{CO}$ to its reduced form produced a new spectral species that resembled that of the reduced $\mathrm{CO}$ complex of a denatured form of cytochrome P450 [30]. Among heme proteins, CBS is unique in that it catalyzes a pyridoxal phosphate (PLP)dependent reaction [31]. The prosthetic heme of this enzyme is coordinated to histidine and cysteine as axial ligands in human and rodents. Although the crystallographic structure of CO-ligated forms has yet to be determined, perturbation of the heme environment by $\mathrm{CO}$, but not by $\mathrm{NO}$, is believed to be communicated to the active site with concomitant inhibition of enzyme activity. Low $K_{\mathrm{i}}$ for $\mathrm{CO}$ suggests that $\mathrm{CBS}$ acts as a CO-specific sensor under physiological conditions.

Gases have the ability to bind to metal-centered prosthetic groups of many proteins. It is likely that gas messengers alter the activity of enzymes with metal-centered prosthetic groups. To test this possibility, we applied metabolome analyses using capillary electrophoresis assisted by mass spectrometry (CE-MS) to search for a candidate enzyme responding to $\mathrm{CO}$ in vivo [29]. In these studies, differential metabolomics display suggested that $\mathrm{CO}$ upregulates metabolites in the remethylation cycle and downregulates those in the transsulfuration pathway (Fig. 1). In vivo pulse-chase analysis of ${ }^{15} \mathrm{~N}$-methionine in livers of control mice and hemin-treated mice in which HO-1 is induced revealed accumulation of ${ }^{15} \mathrm{~N}$-homocysteine and suppression of ${ }^{15} \mathrm{~N}$-cystathionine under the CO-overproducing conditions, suggesting that metabolic flux through CBS is suppressed by $\mathrm{CO}$. The ability of $\mathrm{CO}$ to limit CBS activity as a regulator of the transsulfuration pathway may have diverse impacts on biological systems. As seen in Fig. 2, the HO/CO system stands between the tricarboxylic acid (TCA) cycle and methionine/thiol metabolism. In the following sections, we will discuss pathophysiological consequences brought about by altered metabolic flux in the transsulfuration pathway by the $\mathrm{HO} / \mathrm{CO}$ system.

\section{CO-sensitive CBS and methionine metabolism in cancer}

A growing body of evidence suggests that HO-1 may play a role in tumor induction and can potently increase the growth and spread of tumors. HO-1 expression is often increased in tumor tissues and is further elevated in response to radio-, chemo-, or photodynamic therapy [32]. At present, whether inhibition or induction of HO-1 aggravates development of cancer remains controversial, and prognosis in experiments using cancer cell lines highly depends on the particular cell lines that are analyzed. For instance, in recent studies using HepG2 cells [33], overexpression of wild-type HO-1, but not that of mutant HO-1, decreased the migration of the cancer cells. They have shown that HO-1 plays an important role in hepatocellular carcinoma progression through p38MAPK activation both in vivo and in vitro conditions. On the other hand, HO-1/CO system serves as an antiapoptotic signal followed by activation of Ras-Raf-ERK system that triggers nrf2 to upregulate the enzyme [34]. Recently, Otterbein et al. [35] showed that HO-1/CO pathway participates in the DNA-repair process. Naïve Hmoxnull mice exhibit excessive tissue levels of $\gamma$-histone H2A $(\gamma-\mathrm{H} 2 \mathrm{AX})$, a marker of ongoing and chronic DNA damage. In addition, administration of genotoxic stressors in HO-1deficient fibroblasts resulted in no $\gamma-\mathrm{H} 2 \mathrm{AX}$ foci formation or phosphorylation of $\gamma-\mathrm{H} 2 \mathrm{AX}$. In this model, HO- 1 induction or $\mathrm{CO}$ treatment induced homologous recombinationmediated DNA repair through the activation of the DNA repair kinases, ataxia telangiectasia-mutated (ATM) and ataxia-telangiectasia rad3-related (ATR), while lack of HO1 resulted in the inhibition of phosphorylation of ATM and ATR. Direct molecular target(s) that allow CO binding remains unclear in this study.

Through multiple mechanisms, cancer cells forming tumor might generate considerable amounts of $\mathrm{CO}$ through HO. Recent studies using renal cell carcinoma cells showed roles of mutant fumarate hydratase (FH, Fig. 2) in their development. FH is an enzyme of the TCA cycle that catalyzes the hydration of fumarate to malate. The germline mutation of FH leads to the accumulation of fumarate and the upstream TCA intermediates in the cells [36]. However, no mechanism has been provided to explain the ability of the cell survival without cycling all the TCA intermediates of this metabolic hub. Frezza et al. [36] used genetically modified kidney mouse cells where Fh1 was deleted, and conducted a metabolic simulation in silico to predict and 


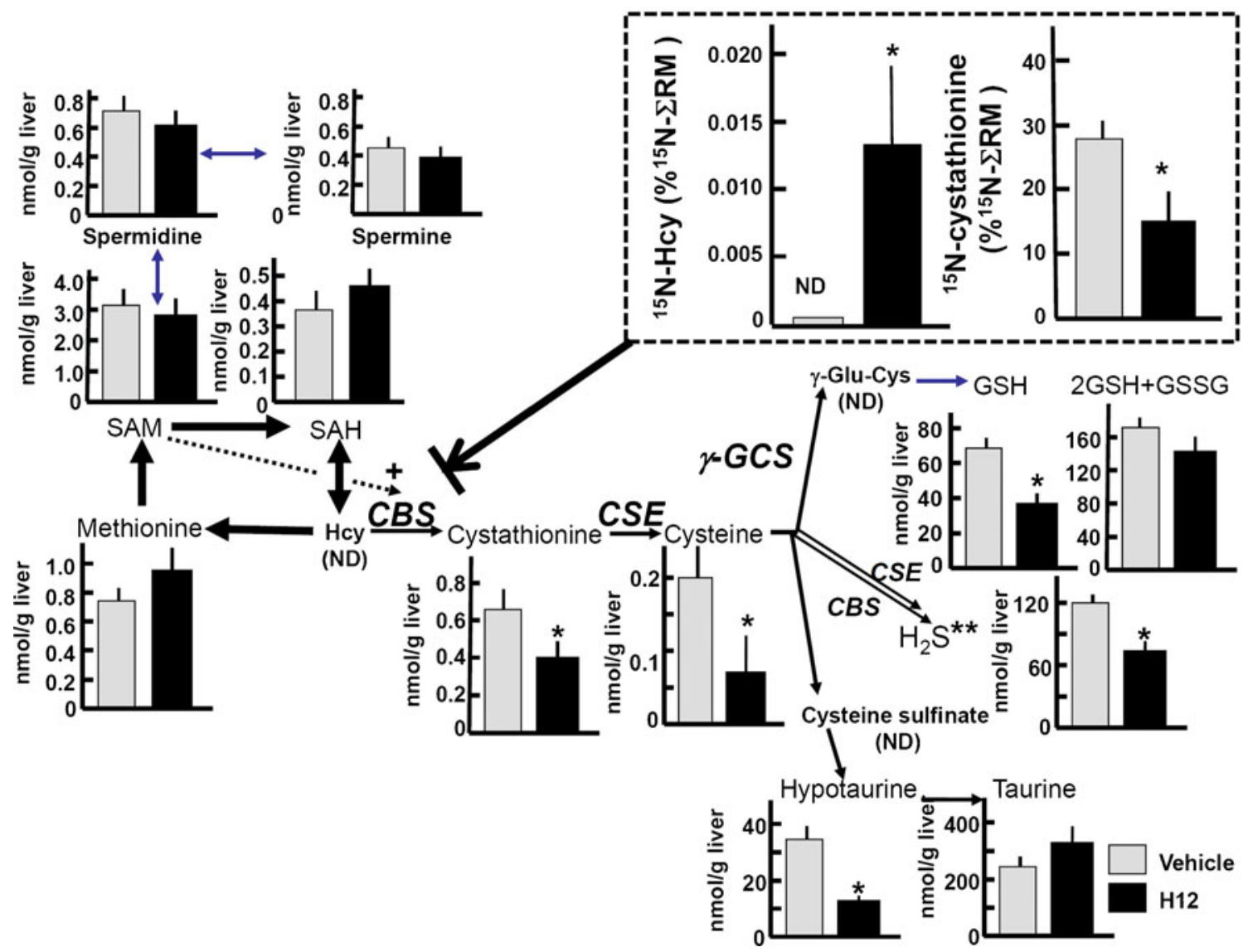

Fig. 1 Differential metabolomics reveals that CO upregulates metabolites in remethylation cycle and downregulates those in transsulfuration pathway. Metabolomic comparison of sulfur-containing amino acids and their derivatives between the heme-overloaded and vehicletreated livers of mice. Differences in hepatic contents of the metabolites between the control and hemin-treated mice. H12 treatment with hemin at $12 \mathrm{~h}$ prior to sampling the liver. Note decreases in transsulfuration metabolites. In vivo pulse-chase analysis indicating conversion rates of ${ }^{15} \mathrm{~N}$-methionine into ${ }^{15} \mathrm{~N}$-homocysteine (Hcy) and ${ }^{15} \mathrm{~N}$ - cystathionine in livers between the groups (dotted square). The amounts of the downstream metabolites were measured at 30 min after the methionine administration. The data in the dotted square were normalized by total amounts of metabolites in remethylation cycle $\left({ }^{15} \mathrm{~N}\right.$-methionine $\left.+{ }^{15} \mathrm{~N}-\mathrm{SAM}+{ }^{15} \mathrm{~N}-\mathrm{SAH}+{ }^{15} \mathrm{~N}-\mathrm{Hcy}=\Sigma \mathrm{RM}\right)$ at 30 min. $N D$ not detected. Data indicate mean $\pm \mathrm{SE}$ of six to eight separate experiments for each group. ${ }^{*} P<0.05$, compared to the vehicle-treated group. Adapted by permission from Wiley: Shintani et al. Hepatology, 49: 141-150, 2009 [29] validate a linear metabolic pathway starting from glutaminolysis and ending with HO-dependent heme degradation and bilirubin formation. This pathway, which involves the biosynthesis and degradation of heme, enables Fh1-deficient cells to use the metabolites of TCA cycle and permits partial mitochondrial NADH production necessary to maintain ATP. They confirmed that targeting this pathway would render Fh1-deficient cells non-viable, while sparing wildtype Fh1-expressing cells. Considering the presence of various mutant TCA enzymes among different types of cancer cells, targeting an aberrant branching pathway might contribute to suppression of the cancer growth and development. At the same time, drawing off TCA intermediates to heme synthesis and degradation serves as a stratagem for survival of certain types of cancer cells.

Upregulation of HO might benefit survival and development through multiple pathways. First, activated heme degradation to provide bilirubin serves as a potent anti-oxidant that actually accounts for the protective mechanism for human neuroblastoma cells that became resistant to GSH-depleting reagents [37, 38]. Second, CO-dependent inhibition of CBS in cancer cell lines triggers upregulation of remethylation metabolites [e.g., methionine (Met), $S$-adenosylmethionine (SAM), $S$ adenosylhomocysteine (SAH) in Fig. 2]; changes in these metabolites determine cellular contents of polyamines that regulate cancer metastasis, and regulate protein methylation and epigenetics [39-41]. On the other hand, CBS inhibition by $\mathrm{CO}$ acutely downregulates transsulfuration metabolites which is followed by recovery of cysteine and GSH, presumably because of compensatory upregulation of $\mathrm{xCT}$ (cystine transporter) that salvages cystine as a precursor to generate these anti-oxidants. Ishimoto et al. have recently reported a 


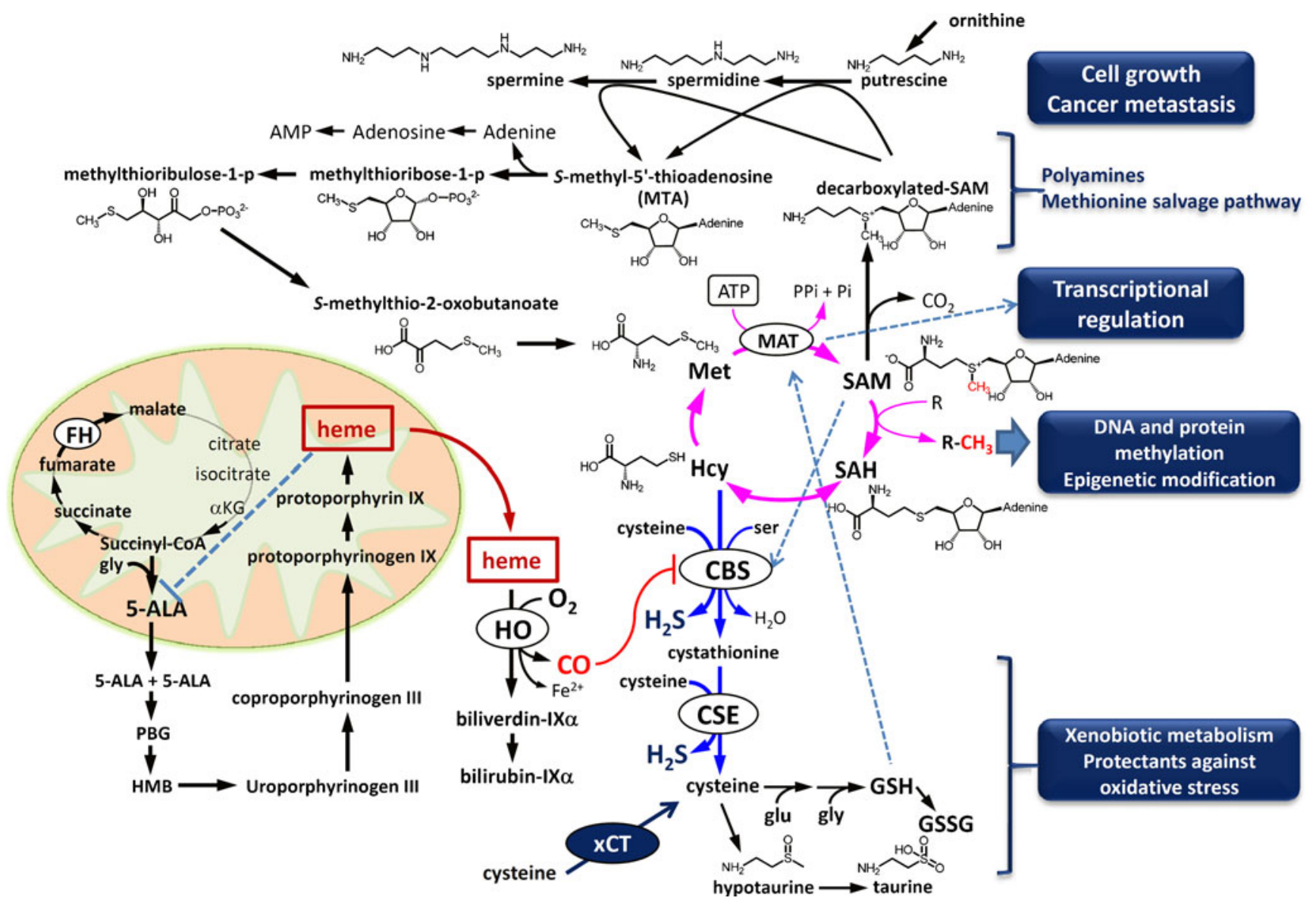

Fig. 2 Possible metabolic pathways modulated by a $\mathrm{CO}$-sensitive CBS inhibition. Not only does CBS inhibition by CO alter remethylation cycle (blue arrows) and transsulfuration pathway (pink arrows) but it may also modulate methionine salvage pathway and polyamine metabolism. Dotted arrows and a line indicate activation and inhibition of corresponding enzymes by metabolites, respectively. ALAS aminolevulinic acid synthase, $F H$ fumarate hydratase, CSE cystathionine $\gamma$ lyase, MAT methionine adenosyl transferase, $\alpha K G \alpha$-ketoglutarate, $A L A$ aminolevulinic acid, $P B G$ porphobilinogen, Hcy homocysteine, $S A M S$-adenosylmethionine, $S A H S$-adenosylhomocysteine role for variant CD44, a receptor for hyaluronic acid, in stabilizing $\mathrm{xCT}$ in the cell membrane that helps GSH accumulation for the cell survival [42]. Upregulation of GSH in tumor also occurs under in vivo conditions (Fig. 3) [43].

As mentioned above, $\mathrm{CO}$ acutely causes a decrease in the GSH amount through its inhibitory action on CBS, as depicted in Fig. 1. However, $\mathrm{CO}$ is known to shift glucose utilization toward pentose phosphate pathway, thereby providing high NADPH to recycle GSSG to its reduced form GSH [44], while molecular mechanism underlying this metabolic shift remains to be solved. Increases in remethylation metabolites by stress-inducible $\mathrm{CO}$ might regulate histone methylation to confirm cancer cell survival [39]. In human U937 monoblastic leukemia cells, knocking down CBS diminishes the responsiveness to $\mathrm{CO}$ or HO-1 induction. These results suggest that CO-sensitive CBS system controls protein methylation which is implicated in epigenetic regulation.
Recent studies by Katoh et al. [45] revealed a novel role of methionine adenosyl transferase (MAT) located in nuclei. They performed proteomics analysis of MafK, revealing its interaction with MATII $\alpha$, a MAT isozyme. MATII $\alpha$ was localized in nuclei and found to form a dense network with chromatin-related proteins including Swi/Snf and NuRD complexes. MATII $\alpha$ was recruited to the Maf recognition element (MARE) at the HO-1 gene. When MATII $\alpha$ was knocked down in a murine hepatoma cell line, expression of HO-1 was repressed at both basal and induced levels. The catalytic activity of MATII $\alpha$, as well as its interacting factors such as MATII $\beta$, BAF53a, CHD4, and PARP1, was required for HO-1 repression. MATII thus serves as a transcriptional corepressor of MafK by interacting with chromatin regulators and supplying SAM for methyltransferases. Nuclear translocation of enzymatically intact MATII causes HO-1 repression, while its mutant expression or loss of MATII causes significant induction of HO-1 through impaired histone methylation at HO-1 locus. Implication of 


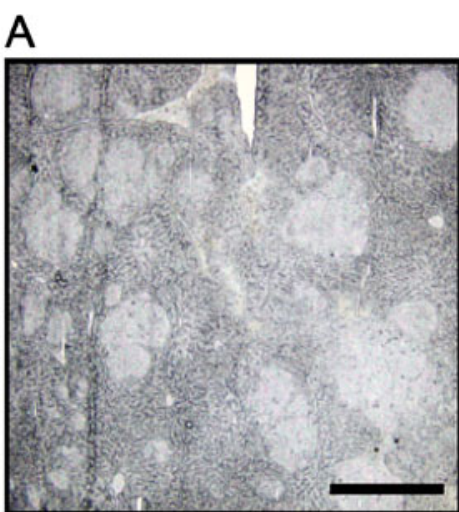

Light microscopic image
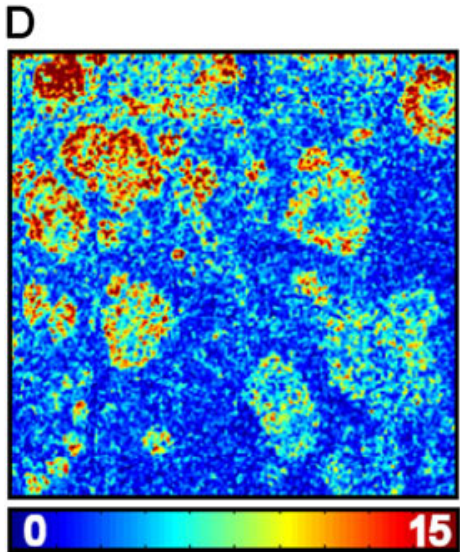

$[\mathrm{GSH}]_{\text {App } \mu \mathrm{mol} / \mathrm{g} \text { tissue }}$
B

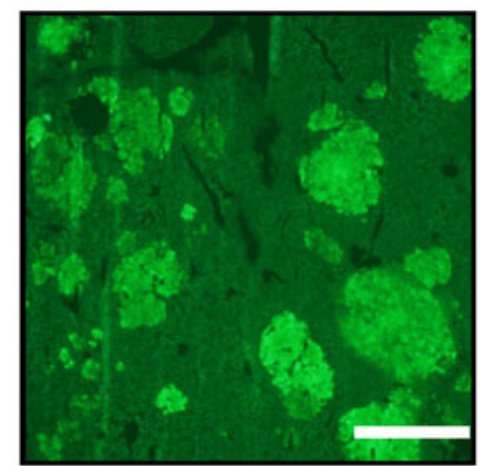

Fluorescent microscopic image venus (green): Tumor

E

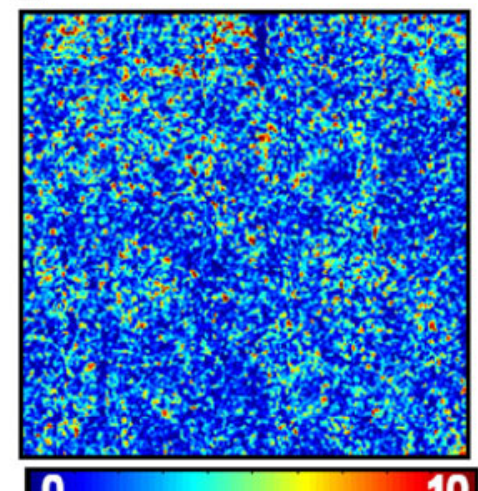

0 [GSSG] $]_{\text {App }} \mu \mathrm{mol} / \mathrm{g}$ tissue
C

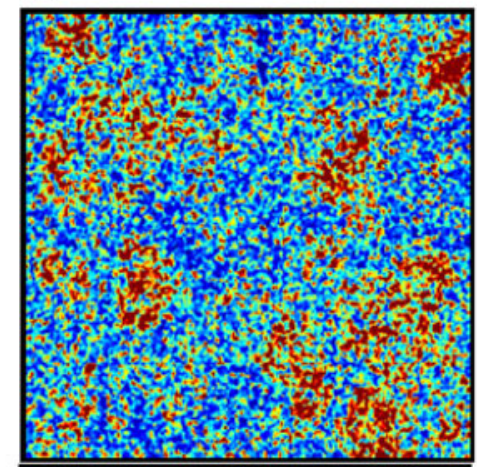

0

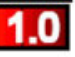

[UDP-HexNAc] App $\mu \mathrm{mol} / \mathrm{g}$ tissue

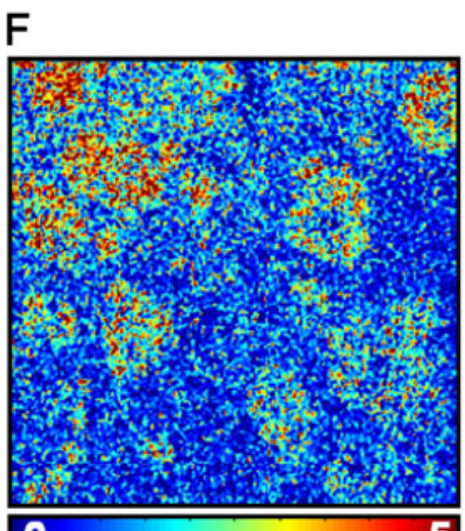

0

$[G S]_{A p p} /[G S S G]_{A p p}$
Fig. 3 Glutathione and UDP-HexNAc as marker metabolites enriched in colon cancer metastasis. a Light-microscopic photograph of intrasplenically injected HCT116 colon cancer cell xenografts in the liver of NOG mice. Scale bar: $500 \mu \mathrm{m}$. b A green fluorescence image of the same specimen shown in (a). c-f Representative imaging mass spectrometry showing spatial distribution of apparent UDP-HexNAc

this novel mechanism for regulation of cancer growth and development should deserve further studies.

\section{CO-dependent $\mathrm{H}_{2} \mathrm{~S}$ inhibition: roles in pathophysiology}

Recent studies revealed that bacteria normally producing $\mathrm{H}_{2} \mathrm{~S}$ acquire antibiotic resistance through mechanisms mitigating oxidative stress imposed by antibiotics [46]. Considering that $\mathrm{H}_{2} \mathrm{~S}$ has the ability to neutralize electrophilic compounds, it is not unreasonable to hypothesize that the gas has the ability to detoxify anti-cancer reagents, some of which are converted to electrophiles in the body. In other words, selective delivery of such compounds might ameliorate toxicity of anti-cancer reagents against the host tissues. Recent studies provided evidence that $\mathrm{H}_{2} \mathrm{~S}$-donating reagents have the potential to suppress cancer development concentration (UDP-HexNAc app), the reduced type of glutathione $\left(\mathrm{GSH}_{\text {app }}\right)$, oxidized glutathione $\left(\mathrm{GSSG}_{\mathrm{app}}\right)$, and $\left(\mathrm{GSH}_{\mathrm{app}}\right) /\left(\mathrm{GSSG}_{\mathrm{app}}\right)$ ratio in the same microscopic field plotted as a heat map, respectively. Adapted by permission from Springer: Kubo et al. Anal Bioanal Chem, 400: 1895-1904, 2011 [43]

[47]. Therefore, it is likely that upregulation of $\mathrm{HO} / \mathrm{CO}$ system might facilitate tumor growth in part by suppressing CBS-derived $\mathrm{H}_{2} \mathrm{~S}$.

CO-sensitive $\mathrm{CBS} / \mathrm{H}_{2} \mathrm{~S}$ system plays crucial roles in homeostasis of organ functions. Several lines of evidence support the concept that $\mathrm{CBS}$ acts as an in vivo $\mathrm{CO}$ sensor. In the mouse liver, the low-end value of endogenous $\mathrm{CO}$ is approximately $5 \mathrm{pmol} \mathrm{CO} / \mathrm{mg}$ tissue [48], suggesting that tissue concentration of $\mathrm{CO}$ is in the micromolar range. Murine hepatocytes express both CO-producing HO-2 [49] and $\mathrm{H}_{2} \mathrm{~S}$-producing CBS. In addition, $\mathrm{HO}-1$ is induced in both hepatocytes and Kupffer cells under stress or disease conditions [50]. The close proximity of the enzyme distributions taken together with measured $\mathrm{CO}$ concentrations, and the kinetics of CBS activity suggests that the enzyme is acting as a CO sensor [51]. Shintani et al. [29] demonstrated that an increase in hepatic $\mathrm{CO}$ content causes global 
Fig. 4 Immunohistochemical localization of HO-2 and CBS in the neurovascular unit of neonatal mouse cerebellar cortex. Neurons and endothelial cells express $\mathrm{HO}-2(\mathbf{a}, \mathbf{b})$, the constitutive CO-producing enzyme, whereas glial cells express CBS (e-h), an $\mathrm{H}_{2} \mathrm{~S}$ producing enzyme. Note that HO-2-positive cells along vessel wall are endothelial in (b), not pericytic, since nuclei of NG2 (pericytic marker) positive cells, stained with TO-PRO-3 (a nucleic acid stain), are completely devoid of CD31 (endothelial marker) labeling in (c). The arteriolar wall is surrounded by NG2positive pericytes in (d), key contractile cells within the neurovascular unit. i Schematic depiction of the localization of HO-2 and CBS in the neurovascular unit. GFAP glial fibrillary acidic protein, an established marker of glial cells; $m l$ molecular layer; $P l$ Purkinje cell layer; $g l$ granular layer; $e$ endothelium; $p$ pericyte. Adapted by permission from National Academy of Sciences, USA: Morikawa et al. PNAS, 109: 1293-1298, 2012 [68]
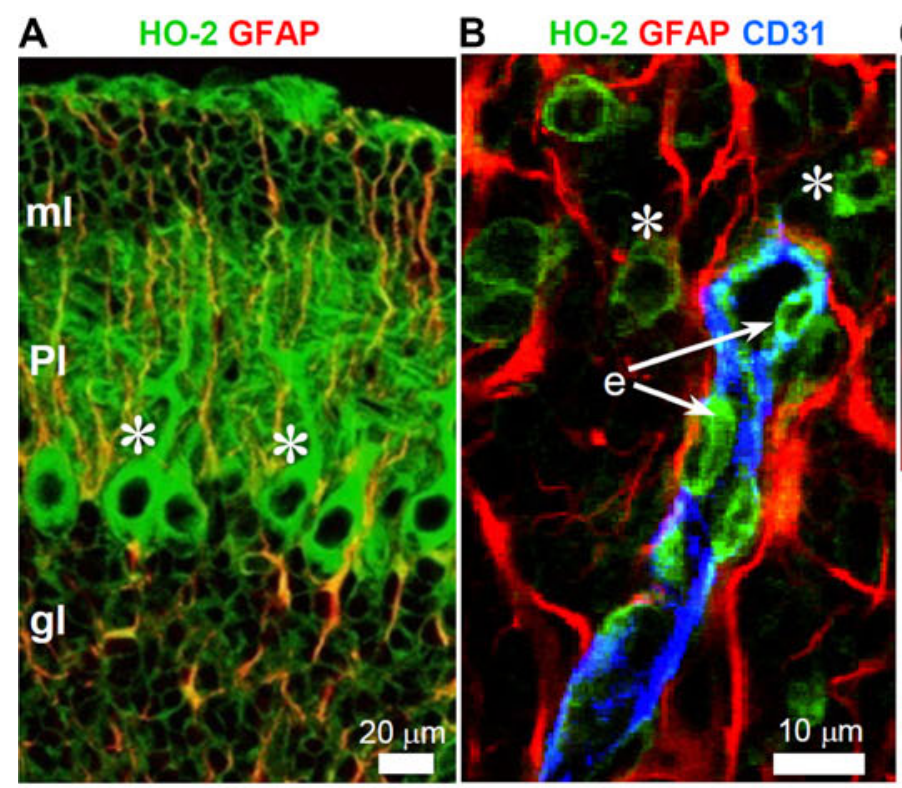

C NG2 CD31 TOPRO
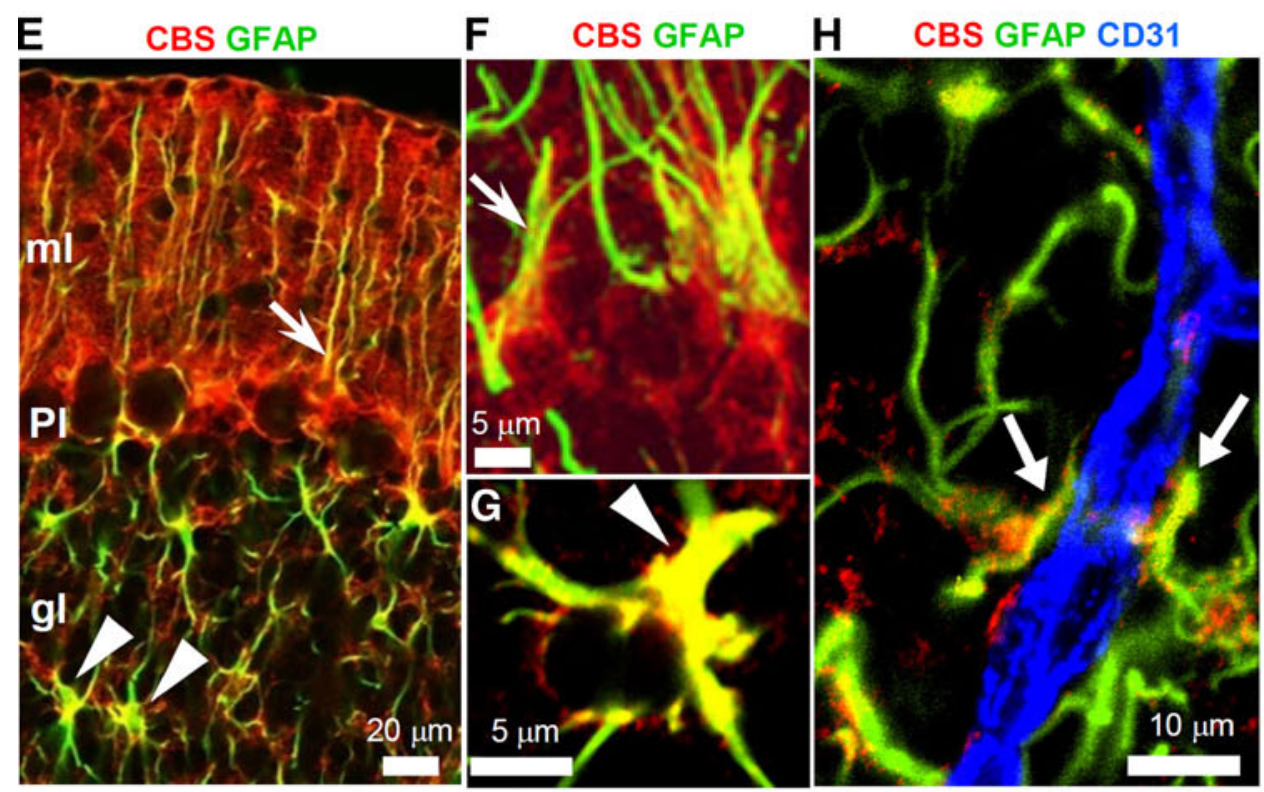

I

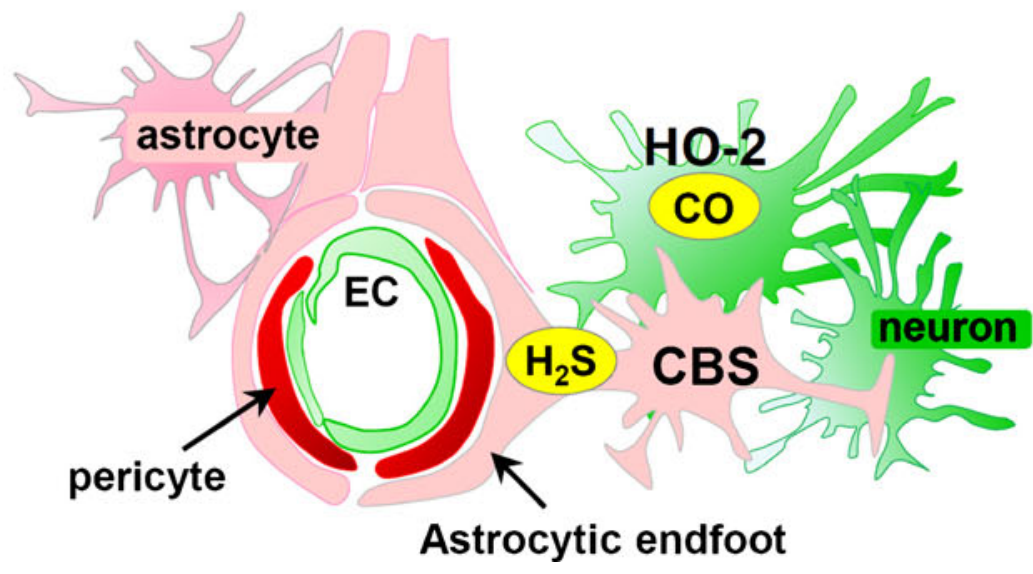



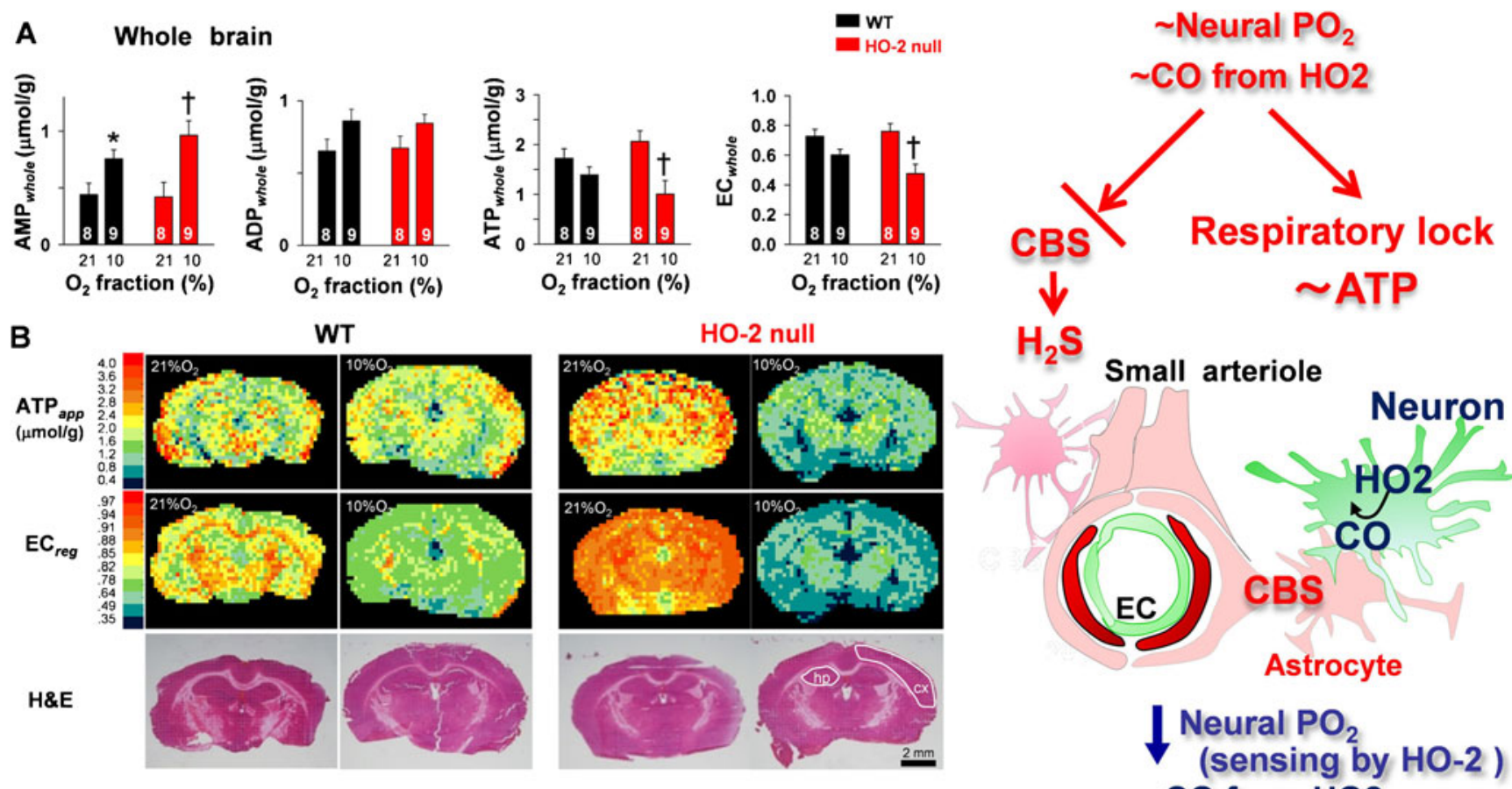

\section{$\mathrm{H}_{2} \mathrm{~S}$ Small arteriole}
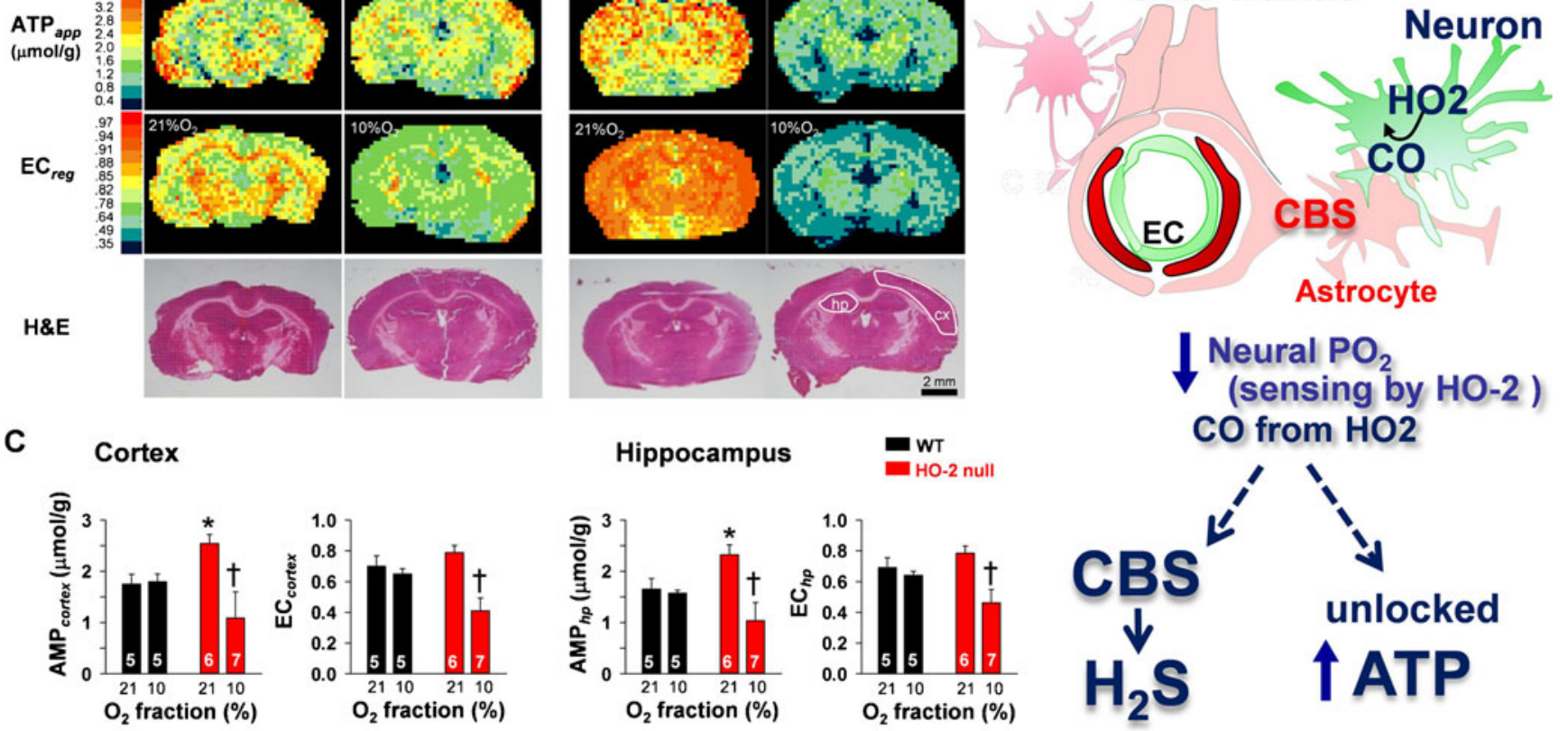

Fig. 5 Impaired ability of HO-2-null mice to maintain ATP levels on exposure to $10 \% \mathrm{O}_{2}$ for $1 \mathrm{~min}$. a Alterations in $\mathrm{AMP}\left(\mathrm{AMP}_{\text {whole }}\right)$, $\mathrm{ADP}$ $\left(\mathrm{ADP}_{\text {whole }}\right), \operatorname{ATP}\left(\mathrm{ATP}_{\text {whole }}\right)$, and energy charge $\left(\mathrm{EC}_{\text {whole }}\right)$ in the whole brain. $* P<0.05$, compared to WT normoxia. $\dagger P<0.05$, compared to HO-2 null normoxia. b Representative imaging mass spectrometry showing spatial distribution of apparent ATP concentration ( $\mathrm{ATP}_{\mathrm{app}}$ ) and energy charge $\left(\mathrm{EC}_{\text {reg }}\right)$. Note the basal increase in ATP in HO-2- null mice. Bottom panels-H\&E staining after imaging mass spectrometry. $c x$ cortex, $h p$ hippocampus. $\mathbf{c}$ Quantitative analysis of regional ATP concentration and energy charge in WT and HO-2-null mice. $* P<0.05$, compared to WT normoxia. $\dagger P<0.05$, compared to HO-2null normoxia. Adapted by permission from National Academy of Sciences, USA: Morikawa et al. PNAS, 109: 1293-1298, 2012 [68] decrease in transsulfuration metabolites such as cystathionine, cysteine, and hypotaurine, as shown in Fig. 1. Administration of a stress-inducible level of CO (as $20 \mu \mathrm{mol} / \mathrm{kg}$ of CO-releasing molecule) caused a decrease in hepatic $\mathrm{H}_{2} \mathrm{~S}$ content to stimulate $\mathrm{HCO}_{3}{ }^{-}$-dependent biliary choleresis. Such a CO-sensitive metabolic adaptation might play a regulatory role in biliary excretion that facilitates the solubility of xenobiotic metabolites under disease conditions or detoxification processes [29, 52-55].

Hypoxia alters $\mathrm{CO}$-sensitive $\mathrm{CBS} / \mathrm{H}_{2} \mathrm{~S}$ pathway to trigger acute adaptive responses for maintaining homeostasis. Although the brain is the most susceptible organ to $\mathrm{O}_{2}$ deprivation, it can increase blood flow in response to hypoxia by several mechanisms. They include potassium [56], adenosine [57, 58], hydrogen ions [59], lactate, and prostaglandin $\mathrm{E}_{2}$ [60]. These adaptive responses are critical for delivery of
$\mathrm{O}_{2}$ and cellular transport of glucose in brain tissue. Readers are referred to an excellent review by Attwell et al. [61] for more comprehensive account on this subject. Here we focus on a gas-mediated cascade that plays a key role in regulating blood flow and energy metabolism. Brain generates large amounts of $\mathrm{CO}$ mainly from constitutive HO-2 reactions [62]. $\mathrm{CO}$ is known to regulate neuronal transmission [9, 63]; however, physiologic roles of $\mathrm{CO}$ in the central nervous system have not been fully understood. In the peripheral nervous systems, $\mathrm{HO}-2$ is an $\mathrm{O}_{2}$ sensor in the carotid body, an organ responsible for sensing $\mathrm{O}_{2}$ levels in arterial blood $[64,65]$. Because HO-2 requires molecular $\mathrm{O}_{2}$ for its activity, it has been proposed that stimulation of carotid body action by hypoxia may reflect in part reduced formation of $\mathrm{CO}$ [66]. A recent study reported that $\mathrm{H}_{2} \mathrm{~S}$ mediates carotid body stimulation by hypoxia and hypoxia-evoked $\mathrm{H}_{2} \mathrm{~S}$ 
generation in the carotid body requires interaction of CSE and HO-2, which generates CO [67] [see Prabhaker NR and Semenza GL, this volume]. In the central nervous system, Morikawa et al. [68] recently demonstrated that HO-2 can function as an $\mathrm{O}_{2}$ sensor in the brain and an $\mathrm{O}_{2}-\mathrm{CO}-\mathrm{H}_{2} \mathrm{~S}$ cascade rapidly mediates hypoxia-induced cerebral vasodilation. In this cascade, hypoxia elicits vasodilation via the coordinate actions of $\mathrm{CO}$ generated by $\mathrm{HO}-2$ and $\mathrm{H}_{2} \mathrm{~S}$ generated by CBS, similar to that proposed in the carotid body. Pericytes, major contractile cells that control the diameter of microvessels [61, 69], are surrounded by CO- and $\mathrm{H}_{2} \mathrm{~S}$-producing cells (Fig. 4). By actually measuring tissue $\mathrm{CO}$ content, these authors showed that HO-2 synthesizes a fair amount of $\mathrm{CO}$ under normoxia and hypoxia reduces $\mathrm{CO}$ production. Since CO tonically inhibits CBS, hypoxia releases the tonic inhibition leading to increased levels of $\mathrm{H}_{2} \mathrm{~S}$ derived from the enzyme that mediate the vasodilation [70] of small arterioles. Such hypoxia-induced vasodilation of arterioles does not occur in CBS-null mice while remaining intact in CSE-null mice [68].

Physiologic consequences of HO-2 loss are intriguing. Namely, basal ATP content in the brain is increased by the deletion of HO-2, suggesting that $\mathrm{CO}$ mildly suppresses ATP production during normoxia. Once the tonic inhibition is relieved by hypoxia, it gives way to the rise in dynamic strength of compensatory ATP maintenance. In HO-2-null mice, neurovascular units lacking such a tonic inhibitory system are unable to compensate ATP levels upon hypoxia (Fig. 5). Such a notion is consistent with previous studies indicating that pharmacological inhibition of $\mathrm{HO}$ increases the basal $\mathrm{O}_{2}$ consumption in the liver [71] and that an increase in endogenous $\mathrm{CO}$ by the enzyme induction inhibits cellular respiration through its inhibitory effects on cytochrome $c$ oxidase [72]. Although the study provides evidence for a novel protective mechanism of neurovascular units against hypoxia that is operated by multiple gases, further investigation is required to reveal functional links between neuronal and microvascular coupling through multiple gases and gas-responsive metabolic systems.

\section{Conclusion}

Stress-inducible and constitutive $\mathrm{CO}$ plays physiologic roles for maintaining homeostasis of cell and organ function. $\mathrm{CO}$ binding to CBS impacts remethylation and transsulfuration pathways, leading to regulation of protein methylation involving epigenetic modification and downregulation of $\mathrm{H}_{2} \mathrm{~S}$, and resultant alterations in cell functions in vivo, respectively. Identification of methylated molecular targets and/or macromolecules responsible for direct $\mathrm{H}_{2} \mathrm{~S}$ binding is needed to establish a concept that gases such as $\mathrm{O}_{2}, \mathrm{CO}$, and
$\mathrm{H}_{2} \mathrm{~S}$ constitute an important class of messengers that regulate metabolic systems through multiple mechanisms.

Acknowledgments M.S. is the leader ERATO (Exploratory Research for Advanced Technology) Gas Biology Project from Japan Science and Technology Agency (JST). This work is supported by JST, ERATO, Suematsu Gas Biology Project, Tokyo 160-8582 to M. S., and in part by Grant-in-Aid for Scientific Research 21500353 and 22710222 from the Japan Society for the Promotion of Science to M.K. and T.Y., respectively. Imaging MS microscopy is supported by Ministry of Economy, Technology and Industry of Japan to M.S, and Grant-in-Aid for SENTAN from JST (A.K.). T.M. is partly supported by Global Center of Excellence Program for Human Metabolomic Systems Biology from the Ministry of Education, Culture, Sports, Science, and Technology Japan (MEXT). Metabolome analyses were supported by Research and Development of the Next-Generation Integrated Simulation of Living Matter, a part of the Development and Use of the Next-Generation Supercomputer Project of MEXT (to M.S.).

Author disclosure statement No competing financial interests exist.

Open Access This article is distributed under the terms of the Creative Commons Attribution License which permits any use, distribution, and reproduction in any medium, provided the original author(s) and the source are credited.

\section{References}

1. Tenhunen R, Marver HS, Schmid R (1968) The enzymatic conversion of heme to bilirubin by microsomal heme oxygenase. Proc Natl Acad Sci U S A 61:748-755

2. Tenhunen R, Marver HS, Schmid R (1969) Microsomal heme oxygenase. Characterization of the enzyme. J Biol Chem 244:6388-6394

3. Yoshida T, Takahashi S, Kikuchi G (1974) Partial purification and reconstitution of the heme oxygenase system from pig spleen microsomes. J Biochem 75:1187-1191

4. Unno M, Matsui T, Chu GC, Couture M, Yoshida T, Rousseau DL, Olson JS, Ikeda-Saito M (2004) Crystal structure of the dioxygenbound heme oxygenase from Corynebacterium diphtheriae: implications for heme oxygenase function. J Biol Chem 279:2105521061

5. Docherty JC, Firneisz GD, Schacter BA (1984) Methene bridge carbon atom elimination in oxidative heme degradation catalyzed by heme oxygenase and NADPH-cytochrome P-450 reductase. Arch Biochem Biophys 235:657-664

6. Noguchi M, Yoshida T, Kikuchi G (1979) Specific requirement of NADPH-cytochrome $c$ reductase for the microsomal heme oxygenase reaction yielding biliverdin IX $\alpha$. FEBS Lett 98:281-284

7. Schuller DJ (2001) Heme Oxygenase. In: Messerschmidt A, Huber R, Poulos TL, Wieghardt K (eds) Handbook of metalloproteins. Wiley, West Sussex, pp 317-327

8. Stocker R, Yamamoto Y, McDonagh AF, Glazer AN, Ames BN (1987) Bilirubin is an antioxidant of possible physiological importance. Science 235:1043-1046

9. Verma A, Hirsch DJ, Glatt CE, Ronnett GV, Snyder SH (1993) Carbon monoxide: a putative neural messenger. Science 259:381384

10. Suematsu M, Goda N, Sano T, Kashiwagi S, Egawa T, Shinoda Y, Ishimura Y (1995) Carbon monoxide: an endogenous modulator of sinusoidal tone in the perfused rat liver. J Clin Invest 96:24312437 
11. Suematsu M, Kashiwagi S, Sano T, Goda N, Shinoda Y, Ishimura Y (1994) Carbon monoxide as an endogenous modulator of hepatic vascular perfusion. Biochem Biophys Res Commun 205:13331337

12. Stone JR, Marletta MA (1998) Synergistic activation of soluble guanylate cyclase by YC-1 and carbon monoxide: implications for the role of cleavage of the iron-histidine bond during activation by nitric oxide. Chem Biol 5:255-261

13. Lewicki JA, Brandwein HJ, Mittal CK, Arnold WP, Murad F (1982) Properties of purified soluble guanylate cyclase activated by nitric oxide and sodium nitroprusside. J Cyclic Nucleotide Res 8:17-25

14. Deinum G, Stone JR, Babcock GT, Marletta MA (1996) Binding of nitric oxide and carbon monoxide to soluble guanylate cyclase as observed with resonance Raman spectroscopy. Biochemistry 35:1540-1547

15. Chen X, Jhee KH, Kruger WD (2004) Production of the neuromodulator $\mathrm{H}_{2} \mathrm{~S}$ by cystathionine $\beta$-synthase via the condensation of cysteine and homocysteine. J Biol Chem 279:52082-52086

16. Meier M, Janosik M, Kery V, Kraus JP, Burkhard P (2001) Structure of human cystathionine $\beta$-synthase: a unique pyridoxal $5^{\prime}$ phosphate-dependent heme protein. EMBO J 20:3910-3916

17. Singh S, Banerjee R (2011) PLP-dependent $\mathrm{H}_{2} \mathrm{~S}$ biogenesis. Biochim Biophys Acta 1814:1518-1527

18. Singh S, Padovani D, Leslie RA, Chiku T, Banerjee R (2009) Relative contributions of cystathionine $\beta$-synthase and $\gamma$ cystathionase to $\mathrm{H}_{2} \mathrm{~S}$ biogenesis via alternative trans-sulfuration reactions. J Biol Chem 284:22457-22466

19. Kabil O, Banerjee R (2010) Redox biochemistry of hydrogen sulfide. J Biol Chem 285:21903-21907

20. Aono S, Honma Y, Ohkubo K, Tawara T, Kamiya T, Nakajima H (2000) CO sensing and regulation of gene expression by the transcriptional activator CooA. J Inorg Biochem 82:51-56

21. Ibrahim M, Kuchinskas M, Youn H, Kerby RL, Roberts GP, Poulos TL, Spiro TG (2007) Mechanism of the CO-sensing heme protein CooA: new insights from the truncated heme domain and UVRR spectroscopy. J Inorg Biochem 101:1776-1785

22. Shelver D, Kerby RL, He Y, Roberts GP (1997) CooA, a COsensing transcription factor from Rhodospirillum rubrum, is a CObinding heme protein. Proc Natl Acad Sci U S A 94:11216-11220

23. Dioum EM, Rutter J, Tuckerman JR, Gonzalez G, Gilles-Gonzalez MA, McKnight SL (2002) NPAS2: a gas-responsive transcription factor. Science 298:2385-2387

24. Reick M, Garcia JA, Dudley C, McKnight SL (2001) NPAS2: an analog of clock operative in the mammalian forebrain. Science 293:506-509

25. Tomita T, Gonzalez G, Chang AL, Ikeda-Saito M, Gilles-Gonzalez MA (2002) A comparative resonance Raman analysis of hemebinding PAS domains: heme iron coordination structures of the BjFixL, AxPDEA1, EcDos, and MtDos proteins. Biochemistry 41:4819-4826

26. Hill M, Pereira V, Chauveau C, Zagani R, Remy S, Tesson L, Mazal D, Ubillos L, Brion R, Asghar K et al (2005) Heme oxygenase-1 inhibits rat and human breast cancer cell proliferation: mutual cross inhibition with indoleamine 2,3-dioxygenase. FASEB J 19:1957-1968

27. Taoka S, Banerjee R (2001) Characterization of NO binding to human cystathionine $\beta$-synthase: possible implications of the effects of $\mathrm{CO}$ and $\mathrm{NO}$ binding to the human enzyme. J Inorg Biochem 87:245-251

28. Taoka S, West M, Banerjee R (1999) Characterization of the heme and pyridoxal phosphate cofactors of human cystathionine $\beta$ synthase reveals nonequivalent active sites. Biochemistry $38: 2738-2744$

29. Shintani T, Iwabuchi T, Soga T, Kato Y, Yamamoto T, Takano N, Hishiki T, Ueno Y, Ikeda S, Sakuragawa T et al (2009)
Cystathionine $\beta$-synthase as a carbon monoxide-sensitive regulator of bile excretion. Hepatology 49:141-150

30. Omura T, Sadano H, Hasegawa T, Yoshida Y, Kominami S (1984) Hemoprotein H-450 identified as a form of cytochrome P-450 having an endogenous ligand at the 6th coordination position of the heme. J Biochem 96:1491-1500

31. Kery V, Bukovska G, Kraus JP (1994) Transsulfuration depends on heme in addition to pyridoxal 5'-phosphate. Cystathionine $\beta$-synthase is a heme protein. J Biol Chem 269:25283-25288

32. Was H, Dulak J, Jozkowicz A (2010) Heme oxygenase-1 in tumor biology and therapy. Curr Drug Targets 11:1551-1570

33. Zou C, Zhang H, Li Q, Xiao H, Yu L, Ke S, Zhou L, Liu W, Wang $\mathrm{W}$, Huang $\mathrm{H}$ et al (2011) Heme oxygenase-1: a molecular brake on hepatocellular carcinoma cell migration. Carcinogenesis 32:1840 1848

34. Banerjee P, Basu A, Datta D, Gasser M, Waaga-Gasser AM, Pal S (2011) The heme oxygenase-1 protein is overexpressed in human renal cancer cells following activation of the Ras-Raf-ERK pathway and mediates anti-apoptotic signal. J Biol Chem 286:33580 33590

35. Otterbein LE, Hedblom A, Harris C, Csizmadia E, Gallo D, Wegiel B (2011) Heme oxygenase-1 and carbon monoxide modulate DNA repair through ataxia-telangiectasia mutated (ATM) protein. Proc Natl Acad Sci U S A 108:14491-14496

36. Frezza C, Zheng L, Folger O, Rajagopalan KN, MacKenzie ED, Jerby L, Micaroni M, Chaneton B, Adam J, Hedley A et al (2011) Haem oxygenase is synthetically lethal with the tumour suppressor fumarate hydratase. Nature 477:225-228

37. Furfaro A, Macay JR, Marengo B, Nitti M, Parodi A, Fenoglio D, Marinari UM, Pronzato MA, Domenicotti C, Traverso N (2011) Resistance of neuroblastoma GI-ME-N cell line to glutathione depletion involves Nrf2 and heme oxygenase-1. Free Radic Biol Med 52:488-496

38. Florczyk U, Golda S, Zieba A, Cisowski J, Jozkowicz A, Dulak J (2011) Overexpression of biliverdin reductase enhances resistance to chemotherapeutics. Cancer Lett 300:40-47

39. Yamamoto T, Takano N, Ishiwata K, Suematsu M (2011) Carbon monoxide stimulates global protein methylation via its inhibitory action on cystathionine $\beta$-synthase. J Clin Biochem Nutr 48:96100

40. Basu I, Locker J, Cassera MB, Belbin TJ, Merino EF, Dong X, Hemeon I, Evans GB, Guha C, Schramm VL (2011) Growth and metastases of human lung cancer are inhibited in mouse xenografts by a transition state analogue of $5^{\prime}$-methylthioadenosine phosphorylase. J Biol Chem 286:4902-4911

41. Kabuyama Y, Litman ES, Templeton PD, Metzner SI, Witze ES, Argast GM, Langer SJ, Polvinen K, Shellman Y, Chan D et al (2009) A mediator of Rho-dependent invasion moonlights as a methionine salvage enzyme. Mol Cell Proteomics $8: 2308-2320$

42. Ishimoto T, Nagano O, Yae T, Tamada M, Motohara T, Oshima H, Oshima M, Ikeda T, Asaba R, Yagi H et al (2011) CD44 variant regulates redox status in cancer cells by stabilizing the $\mathrm{xCT}$ subunit of system xc(-) and thereby promotes tumor growth. Cancer Cell 19:387-400

43. Kubo A, Ohmura M, Wakui M, Harada T, Kajihara S, Ogawa K, Suemizu H, Nakamura M, Setou M, Suematsu M (2011) Semiquantitative analyses of metabolic systems of human colon cancer metastatic xenografts in livers of superimmunodeficient NOG mice. Anal Bioanal Chem 400:1895-1904

44. Takano N, Yamamoto T, Adachi T, Suematsu M (2010) Assessing a shift of glucose biotransformation by LC-MS/MS-based metabolome analysis in carbon monoxide-exposed cells. Adv Exp Med Biol 662:101-107

45. Katoh Y, Ikura T, Hoshikawa Y, Tashiro S, Ito T, Ohta M, Kera Y, Noda T, Igarashi K (2011) Methionine adenosyltransferase II 
serves as a transcriptional corepressor of Maf oncoprotein. Mol Cell 41:554-566

46. Shatalin K, Shatalina E, Mironov A, Nudler E (2011) $\mathrm{H}_{2} \mathrm{~S}$ : a universal defense against antibiotics in bacteria. Science 334:986-990

47. Ma K, Liu Y, Zhu Q, Liu CH, Duan JL, Tan BK, Zhu YZ (2011) $\mathrm{H}_{2} \mathrm{~S}$ donor, $S$-propargyl-cysteine, increases CSE in SGC-7901 and cancer-induced mice: evidence for a novel anti-cancer effect of endogenous $\mathrm{H}_{2} \mathrm{~S}$ ? PLoS One 6:e20525

48. Vreman HJ, Wong RJ, Kadotani T, Stevenson DK (2005) Determination of carbon monoxide $(\mathrm{CO})$ in rodent tissue: effect of heme administration and environmental CO exposure. Anal Biochem 341:280-289

49. Goda N, Suzuki K, Naito M, Takeoka S, Tsuchida E, Ishimura Y, Tamatani T, Suematsu M (1998) Distribution of heme oxygenase isoforms in rat liver. Topographic basis for carbon monoxidemediated microvascular relaxation. J Clin Invest 101:604-612

50. Makino N, Suematsu M, Sugiura Y, Morikawa H, Shiomi S, Goda N, Sano T, Nimura Y, Sugimachi K, Ishimura Y (2001) Altered expression of heme oxygenase-1 in the livers of patients with portal hypertensive diseases. Hepatology 33:32-42

51. Kajimura M, Fukuda R, Bateman RM, Yamamoto T, Suematsu M (2010) Interactions of multiple gas-transducing systems: hallmarks and uncertainties of $\mathrm{CO}, \mathrm{NO}$, and $\mathrm{H}_{2} \mathrm{~S}$ gas biology. Antioxid Redox Signal 13:157-192

52. Norimizu S, Kudo A, Kajimura M, Ishikawa K, Taniai H, Yamaguchi T, Fujii K, Arii S, Nimura Y, Suematsu M (2003) Carbon monoxide stimulates mrp2-dependent excretion of bilirubin-IX $\alpha$ into bile in the perfused rat liver. Antioxid Redox Signal 5:449-456

53. Kyokane T, Norimizu S, Taniai H, Yamaguchi T, Takeoka S, Tsuchida E, Naito M, Nimura Y, Ishimura Y, Suematsu M (2001) Carbon monoxide from heme catabolism protects against hepatobiliary dysfunction in endotoxin-treated rat liver. Gastroenterology 120:1227-1240

54. Mori M, Suematsu M, Kyokane T, Sano T, Suzuki H, Yamaguchi T, Ishimura Y, Ishii H (1999) Carbon monoxide-mediated alterations in paracellular permeability and vesicular transport in acetaminophen-treated perfused rat liver. Hepatology 30:160-168

55. Fujii K, Sakuragawa T, Kashiba M, Sugiura Y, Kondo M, Maruyama K, Goda N, Nimura Y, Suematsu M (2005) Hydrogen sulfide as an endogenous modulator of biliary bicarbonate excretion in the rat liver. Antioxid Redox Signal 7:788-794

56. Vyskocil F, Kritz N, Bures J (1972) Potassium-selective microelectrodes used for measuring the extracellular brain potassium during spreading depression and anoxic depolarization in rats. Brain Res 39:255-259

57. Winn HR, Rubio GR, Berne RM (1981) The role of adenosine in the regulation of cerebral blood flow. J Cereb Blood Flow Metab 1:239-244
58. Miekisiak G, Kulik T, Kusano Y, Kung D, Chen JF, Winn HR (2008) Cerebral blood flow response in adenosine 2a receptor knockout mice during transient hypoxic hypoxia. J Cereb Blood Flow Metab 28:1656-1664

59. Lassen NA (1968) Brain extracellular $\mathrm{pH}$ : the main factor controlling cerebral blood flow. Scand J Clin Lab Invest 22:247-251

60. Gordon GR, Choi HB, Rungta RL, Ellis-Davies GC, MacVicar BA (2008) Brain metabolism dictates the polarity of astrocyte control over arterioles. Nature 456:745-749

61. Attwell D, Buchan AM, Charpak S, Lauritzen M, Macvicar BA, Newman EA (2010) Glial and neuronal control of brain blood flow. Nature 468:232-243

62. Ishikawa M, Kajimura M, Adachi T, Maruyama K, Makino N, Goda N, Yamaguchi T, Sekizuka E, Suematsu M (2005) Carbon monoxide from heme oxygenase-2 is a tonic regulator against NOdependent vasodilatation in the adult rat cerebral microcirculation. Circ Res 97:e104-e114

63. Zakhary R, Gaine SP, Dinerman JL, Ruat M, Flavahan NA, Snyder SH (1996) Heme oxygenase 2: endothelial and neuronal localization and role in endothelium-dependent relaxation. Proc Natl Acad Sci U S A 93:795-798

64. Prabhakar NR (1995) Gases as chemical messengers in the carotid body. Role of nitric oxide and carbon monoxide in chemoreception. Adv Exp Med Biol 393:309-312

65. Williams SE, Wootton P, Mason HS, Bould J, Iles DE, Riccardi D, Peers C, Kemp PJ (2004) Hemoxygenase-2 is an oxygen sensor for a calcium-sensitive potassium channel. Science 306:2093-2097

66. Prabhakar NR (1999) NO and CO as second messengers in oxygen sensing in the carotid body. Respir Physiol 115:161-168

67. Peng YJ, Nanduri J, Raghuraman G, Souvannakitti D, Gadalla MM, Kumar GK, Snyder SH, Prabhakar NR (2010) $\mathrm{H}_{2} \mathrm{~S}$ mediates $\mathrm{O}_{2}$ sensing in the carotid body. Proc Natl Acad Sci U S A 107:10719-10724

68. Morikawa T, Kajimura M, Nakamura T, Hishiki T, Nakanishi T, Yukutake Y, Nagahata Y, Ishikawa M, Hattori K, Takenouchi T et al (2012) Hypoxic regulation of the cerebral microcirculation is mediated by a carbon monoxide-sensitive hydrogen sulfide pathway. Proc Natl Acad Sci U S A 109:1293-1298

69. Peppiatt CM, Howarth C, Mobbs P, Attwell D (2006) Bidirectional control of CNS capillary diameter by pericytes. Nature 443:700-704

70. Zhao W, Zhang J, Lu Y, Wang R (2001) The vasorelaxant effect of $\mathrm{H}_{2} \mathrm{~S}$ as a novel endogenous gaseous $\mathrm{K}_{\text {ATP }}$ channel opener. EMBO J 20:6008-6016

71. Sano T, Shiomi M, Wakabayashi Y, Shinoda Y, Goda N, Yamaguchi T, Nimura Y, Ishimura Y, Suematsu M (1997) Endogenous carbon monoxide suppression stimulates bile acid-dependent biliary transport in perfused rat liver. Am J Physiol 272:G1268-G1275

72. D'Amico G, Lam F, Hagen T, Moncada S (2006) Inhibition of cellular respiration by endogenously produced carbon monoxide. $\mathrm{J}$ Cell Sci 119:2291-2298 